\title{
Agenesis of the isthmus of the thyroid gland
}

\begin{abstract}
Uğur Kesici (1), Sevgi Kesici² (1)
The thyroid is an endocrine gland composed of two lobes connected by the isthmus tissue. Thyroid isthmus agenesis is a rare condition, and only a few cases have been reported in the literature. Here, we discuss the case of a 56-yearold female patient in whom agenesis of the thyroid isthmus was discovered incidentally during surgery for a multinodular goitre. When agenesis of the isthmus is found, associated thyroid lobe agenesis and the presence of ectopic thyroid tissue must be considered. In addition, associated autoimmune thyroid nodule, thyroiditis, primary thyroid carcinoma, metastasis, and amyloidosis must be considered in the differential diagnosis. Preoperative awareness of potential agenesis of the isthmus and its associated thyroid anomalies in patients with planned thyroid surgery will significantly contribute to safety during surgical procedures and result in fewer surgery-related complications. Keywords: Agenesis, isthmus, thyroid
\end{abstract}

ORCID IDs of the authors: U.K. 0000-0001-7457-6625 S.K. 0000-0002-8276-6039

\section{Cite this paper as:} Kesici U, Kesici S. Agenesis of the isthmus of the thyroid gland. Turk J Surg 2018; 34: 60-61.

'Department of General Surgery, Giresun University Faculty of Medicine, Giresun, Turkey

${ }^{2}$ Department of Anesthesiology and Reanimation, Giresun University Faculty of Medicine, Giresun, Turkey

\section{Address for Correspondence} Uğur Kesici e-mail:ugurkesici77@mynet.com

Received: 12.01.2015

Accepted: 14.04.2015

Available Online Date: 14.07.2015

\section{CCopyright 2018}

by Turkish Surgical Association
Available online at www.turkjsurg.com

\section{INTRODUCTION}

The thyroid gland is an endocrine gland composed of two lobes connected by the isthmus tissue (1). The isthmus is localized at the level of the second and third tracheal rings (2). A wide range of morphological variations of the isthmus, such as hypoplasia, ectopy, hemiagenesis, and agenesis as well as developmental anomalies have been described in the literature. Thyroid isthmus agenesis is rare, and only a few cases have been identified (3). Here, we discuss the case of a patient in whom agenesis of the thyroid isthmus was discovered incidentally during total thyroidectomy for multinodular goitre.

\section{CASE PRESENTATION}

The patient was a 56-year-old female patient who provided her consent for the publication of this case report. She underwent surgery for multinodular goitre, and agenesis of the isthmus was determined intraoperatively. Her past medical history was significant for hypertension and total abdominal hysterectomy with bilateral salpingo-oophorectomy. Preoperatively, physical examination revealed palpable nodules in both thyroid lobes, and neck ultrasonography (USG) revealed multiple hypoechoic thyroid nodules, the largest being $4 \mathrm{~cm}$ and located in the right lobe. Total thyroidectomy was planned. Laboratory analyses were normal. Total thyroidectomy was performed under general anaesthesia with neuromuscular monitoring. It was discovered that the patient had no thyroid isthmus tissue during intraoperative surgical exploration. Intra-operative images of the patient and images of both thyroid lobes after surgical excision are shown in Figures 1 and 2, respectively.

\section{DISCUSSION}

Although the incidence of thyroid isthmus agenesis has been reported to range between $0.5 \%$ and $10 \%$, the precise incidence rate is unknown $(4,5)$. Because a few cases have been reported, data regarding the incidence of thyroid agenesis are mainly based on cadaver series. Dixit et al. (1) reported the rate of isthmus agenesis to be $14.6 \%$ in a series of 41 cadavers, whereas Ranade et al. (6) reported a rate of $33 \%$ in a series of 105 cadavers. Therefore, with such a limited number of cadaver series available in the literature, the data on the incidence of isthmus agenesis is considered to be insufficient.

The etiology of isthmus agenesis is also not completely known. It has been reported that it may be related to genetic factors, developmental anomalies, and mutations of chromosome 22 and thyroid transcription factor (TITF) 1-2 genes $(4,7,8)$.

Clinically, scintigraphy with an overload of thyroid stimulating hormone (TSH) can be used to diagnose agenesis of the isthmus. It can also be diagnosed using USG, computed tomography (CT), and magnetic resonance imaging (MRI) or during thyroid surgery (1). In this case report, agenesis of the isthmus was determined during thyroid surgery. In our patient, the reason for not determining agenesis of the isthmus by preoperative neck USG may be because of the expansion of the thyroid lobe into the midline by the large nodule in the right lobe. Patients with isthmus agenesis are generally euthyroid but hypothyroidism or hyperthyroidism may be seen (5). In our case, thyroid function was normal. 


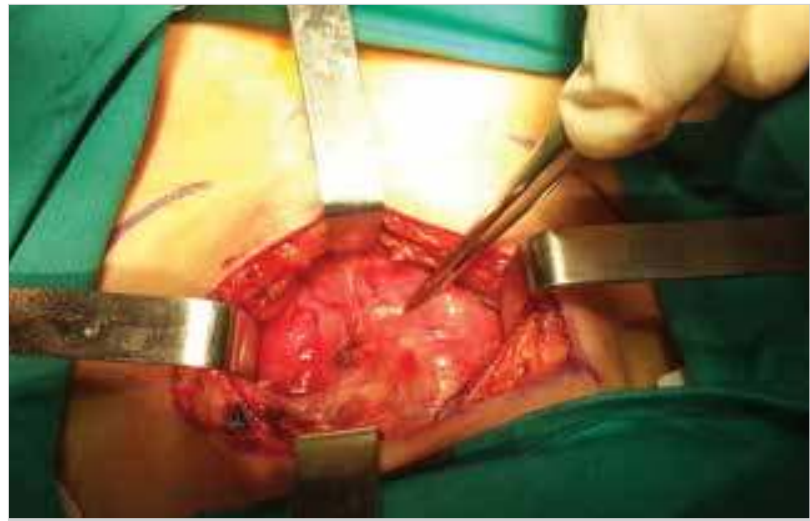

Figure 1. Perioperative image of the patient

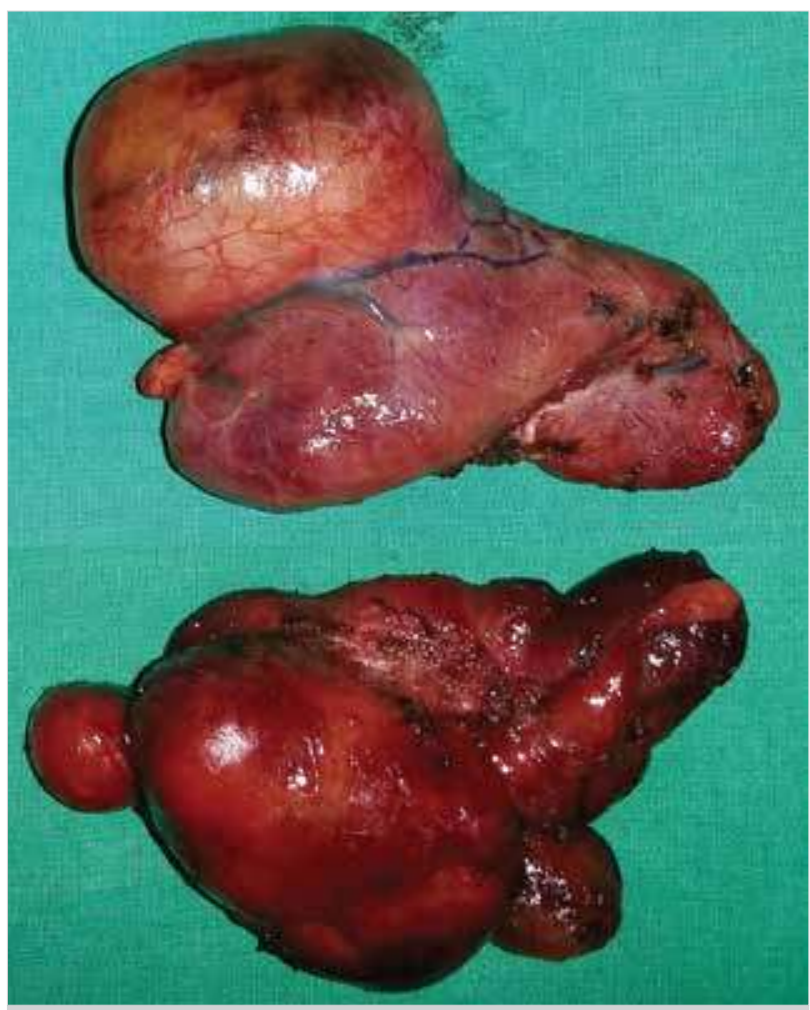

Figure 2. Thyroid tissue after surgical excision

When agenesis of the isthmus is determined, diseases such as autoimmune thyroid nodule, thyroiditis, primary thyroid carcinoma, metastasis, and amyloidosis must be considered in the differential diagnosis. Agenesis of the isthmus can be associated with agenesis of the thyroid lobe, ectopic thyroid tissue, or parathyroid hyperplasia $(1,5,9)$. Bearing these associations in mind may contribute to safer surgical procedures and fewer surgery-related complications. Therefore, the importance of diagnosing agenesis of the isthmus and other associated thyroid anomalies in preoperative assessment should be remembered in patients for whom thyroid surgery is planned.

\section{CONCLUSION}

Agenesis of the thyroid gland is rare. When agenesis of the isthmus is determined, its association with agenesis of the thyroid lobe or the presence of ectopic thyroid tissue must be kept in mind. In addition, diseases such as autoimmune thyroid nodule, thyroiditis, primary thyroid carcinoma, metastasis, and amyloidosis must be considered in the differential diagnosis. It should be remembered that the determination of agenesis of the isthmus and other thyroid anomalies during preoperative assessment in the patients for whom thyroid surgery is planned would contribute significantly to safer surgical procedures and fewer surgery-related complications.

Informed Consent: Written informed consent was obtained from patient who participated in this case.

Peer-review: Externally peer-reviewed.

Author Contributions: Concept - U.K.; Design - U.K., S.K.; Supervision - U.K., S.K.; Funding - U.K., S.K.; Materials - U.K.; Data Collection and/or Processing - U.K., S.K.; Analysis and/or Interpretation - U.K., S.K.; Literature Review - U.K., S.K.; Writer - U.K.; Critical Review - U.K., S.K.

Conflict of Interest: No conflict of interest was declared by the authors.

Financial Disclosure: The authors declared that this study has received no financial support.

\section{REFERENCES}

1. Dixit D, Shilpa MB, Harsh MP, Ravishankar MV. Agenesis of isthmus of thyroid gland in adult human cadavers: a case series. Cases J 2009; 2: 6640. [CrossRef]

2. Taty-Anna K, Farihah HS, Norzana AG, Farida H, Das S. Absence of the isthmus of the thyroid gland: anatomical and clinical considerations. Clin Ter 2012; 163: 503-504.

3. Kumar GP, Satyanarayana N, Vishwakarma N, Guha R, Dutta AK, Sunitha P. Agenesis of isthmus of thyroid gland, its embryological basis and clinical significance--a case report. Nepal Med Coll J 2010; 12: 272-274.

4. Ozkan OF, Asık M, Toman H, Ozkul F, Cıkman O, Karaayvaz M. Agenesis of isthmus of the thyroid gland in a patient with gravesbasedow disease and a solitary nodule. Case Rep Surg 2013: 608481. [CrossRef]

5. Vayisoglu Y, Ozcan C, Gen R, Eti CM, Sut H, Gorur K. Thyroid isthmus agenesis associated with thyroid papillary carcinoma. J Craniofac Surg 2013; 24: e428-429. [CrossRef]

6. Ranade AV, Rai R, Pai MM, Nayak SR, Prakash, Krisnamurthy A, et al. Anatomical variation of the thyroid gland: possible surgical implications. Singapore Med J 2008; 49: 831-834.

7. Sankar KD, Bhanu PS, Bapuji P. Agenesis of isthmus of thyroid gland with embryological and clinical basis. Narayana Medical Journal 2012; 1: 32-34.

8. Gangbo F, Lacombe D, Alberti EM, Taine L, Saura R, Carles DN. Trisomy 22 with thyroid isthmus agenesis and absent gall bladder. Genetic Counseling 2004; 15: 311-315.

9. Pastor VJF, Gil VJA, De Paz Fernández FJ, Cachorro MB. Agenesis of the thyroid isthmus. Eur J Anat 2006; 10: 83-84. 